\section{Reduced tree growth in the semiarid United States due to asymmetric responses to intensifying precipitation extremes}

\author{
Matthew P. Dannenberg ${ }^{1,2 *}$, Erika K. Wise ${ }^{3}$, William K. Smith ${ }^{2}$ \\ Earth's hydroclimatic variability is increasing, with changes in the frequency of extreme events that may neg- \\ atively affect forest ecosystems. We examined possible consequences of changing precipitation variability using \\ tree rings in the conterminous United States. While many growth records showed either little evidence of pre- \\ cipitation limitation or linear relationships to precipitation, growth of some species (particularly those in semi- \\ arid regions) responded asymmetrically to precipitation such that tree growth reductions during dry years were \\ greater than, and not compensated by, increases during wet years. The U.S. Southwest, in particular, showed a \\ large increase in precipitation variability, coupled with asymmetric responses of growth to precipitation. Simu- \\ lations suggested roughly a twofold increase in the probability of large negative growth anomalies across the \\ Southwest resulting solely from 20th century increases in variability of cool-season precipitation. Models project \\ continued increases in precipitation variability, portending future growth reductions across semiarid forests of the \\ western United States.
}

\section{INTRODUCTION}

Anthropogenic emissions of carbon dioxide from fossil fuels and land use change have warmed Earth by approximately $1^{\circ} \mathrm{C}$ since the late 19 th century (1), with virtual certainty of continued warming during the 21st century (2). Warming leads to an accelerated hydrologic cycle due to the exponential relationship between temperature and saturation vapor pressure (3) and to changes in moisture delivery systems such as El Niño (4), jet streams (5), and storm tracks (6). While changes in mean precipitation are uncertain and vary by region (2), changes in temperature will likely result in higher vapor pressure deficit (VPD) and higher precipitation variability $(2,3)$. Globally, changes in the variability of precipitation are likely to be larger than changes in mean precipitation and nearly ubiquitous across all regions (3).

How vegetated ecosystems respond to these hydroclimatic changes remains unknown, with important implications for ecosystem services, hydrological feedbacks via changes in evapotranspiration, and biophysical and biogeochemical feedbacks to the climate system. Evidence suggests that higher VPD, which can initiate stomatal closure and increase hydraulic stress, generally leads to lower assimilation and plant growth $(7,8)$, and has been implicated in widespread forest dieoff across the globe (7, 9-11). However, increases in VPD will co-occur with likely increases in the variability of precipitation, with uncertain consequences for ecosystem carbon uptake. If plant growth and primary production respond asymmetrically or nonlinearly to precipitation, then an increase in precipitation variability can lead to longterm growth trends even with negligible changes in mean precipitation (12). If dry extremes reduce growth more than wet extremes increase growth, then an increase in precipitation variability will result in reduced growth during dry years that is not offset by increased growth during wet years, leading to both increased interannual variability and long-term growth declines.

${ }^{1}$ Department of Geographical and Sustainability Sciences, University of lowa, lowa City, IA, USA. ${ }^{2}$ School of Natural Resources and the Environment, University of Arizona, Tucson, AZ, USA. ${ }^{3}$ Department of Geography, University of North Carolina, Chapel Hill, NC, USA.

${ }^{*}$ Corresponding author. Email: matthew-dannenberg@uiowa.edu
Experimental manipulations and multi-decade observational datasets have been used to examine these asymmetries in growth responses to precipitation, particularly for grass and shrub species (13-15). However, experiments are often conducted over short time periods and on a limited range of species, and observational datasets tend to be limited in both spatial and temporal scope. Moreover, previous research has generally focused on annual precipitation, but in many cases, forest growth and productivity have distinct responses to sub-annual variation in water supply (16-18). In other words, when water is delivered may matter as much as the amount of water that is delivered. Here, we use more than 100 years of tree-ring widths from across the conterminous United States (fig. S1) in combination with historical, high-resolution precipitation estimates to examine asymmetries in the relationship between tree growth and precipitation. Further, we examine how these asymmetries vary as a function of (i) species, (ii) seasonality of precipitation, and (iii) regional aridity. Last, we examine the implications of asymmetric precipitation-growth relationships in the context of a more variable hydroclimate. Because precipitation variability has increased and will likely continue to increase, a more robust understanding of the impacts of increasing precipitation variability on tree growth is a key step toward accurate forecasts of climate change impacts on forest ecosystems.

\section{RESULTS}

We assessed changes in interannual precipitation variability during the October to March "cool season" and April to September "warm season" using the coefficient of variation of precipitation (CVP; Materials and Methods) (19). The CVP varied spatially across the conterminous United States (Fig. 1, A and B), with high variability (relative to mean precipitation) in the dry southwestern United States and lower variability in more mesic regions. In general, variability did not change substantially in regions with low CVP, such as most of the eastern and Pacific Northwest of the United States (Fig. 1, C to F). In contrast, regions with high CVP became even more variable during the 20th century, particularly the U.S. Southwest (Fig. 1, C to F). While the density of meteorological stations used to estimate gridded precipitation is 
Cool season

A

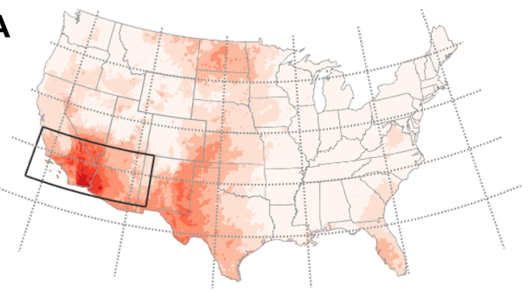

C

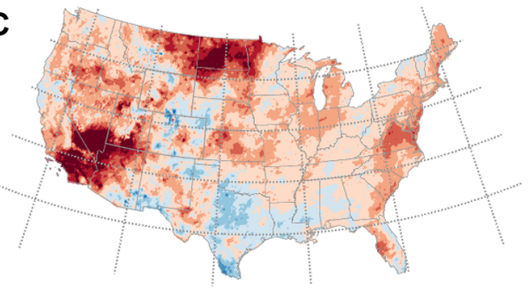

E

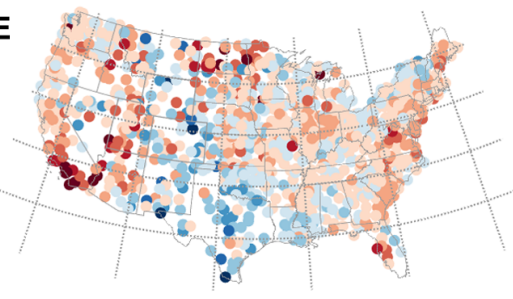

G

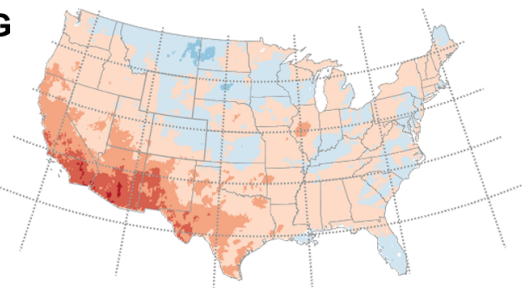

Warm season

B

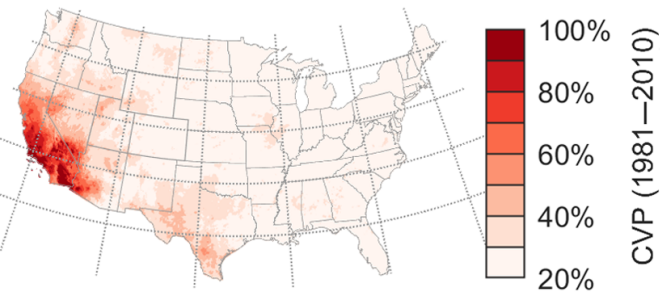

D

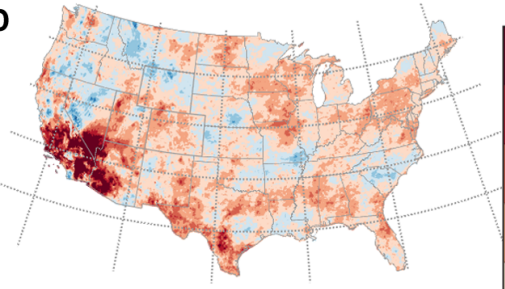

$\mathbf{F}$
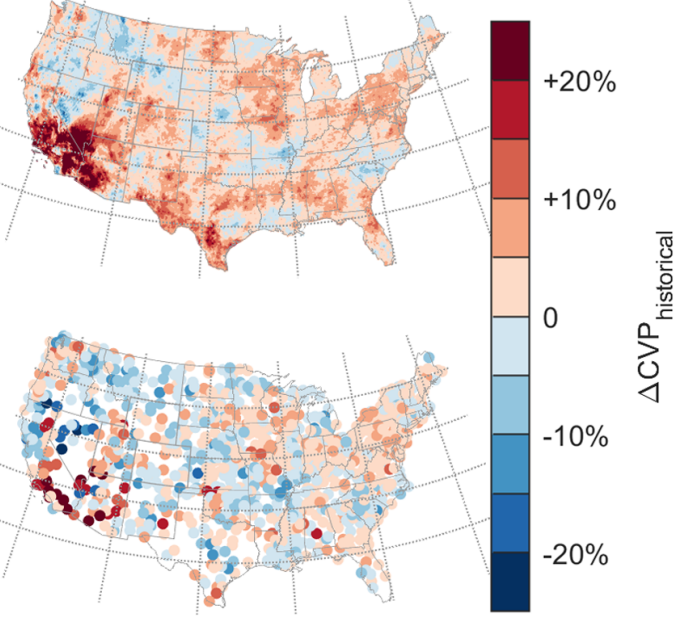

H

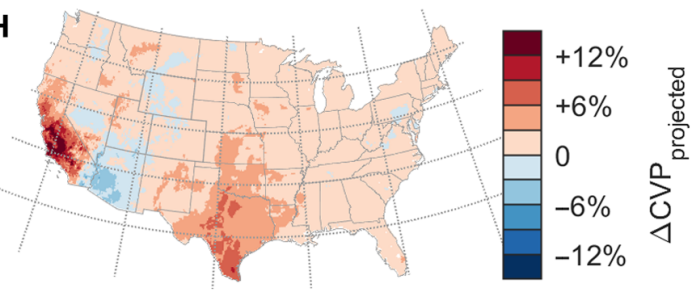

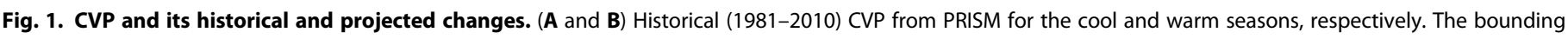

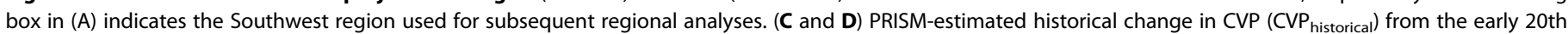

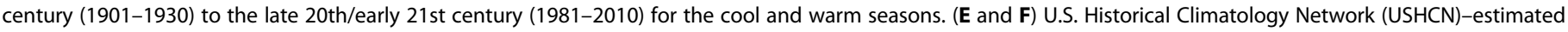

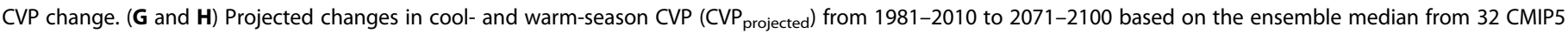

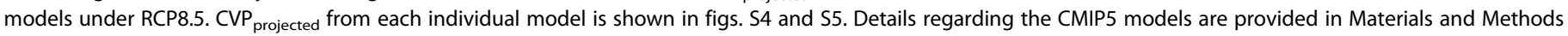
and the Supplementary Materials.

relatively sparse during the earliest period (1901-1930), gridded and station precipitation datasets are in close agreement on observed changes in CVP (Fig. 1, C to F, and fig. S2), and the strong increase in CVP in the Southwest is robust to choice of time period, with a nearly monotonic increase in CVP over the historical record (fig. S3). Precipitation projections from an ensemble of models included in CMIP5, statistically downscaled using bias correction and spatial disaggregation $(20,21)$, show further increases in CVP under the RCP8.5 scenario over the next century, with large projected increases in cool-season CVP over the U.S. Southwest (Fig. 1 G and fig. S4) and warm-season CVP in both Texas and southern California (Fig. $1 \mathrm{H}$ and fig. S5). While there is some disagreement among the models on the magnitude (and in some regions, the direction) of the change in CVP (figs. S4 and S5), the majority of the models agree on a large increase in CVP in the southwestern United States. Theory also predicts that warming will drive increases in precipitation variability (3) and "hydroclimatic intensity" (22) due to the physical relationship between temperature and the water holding capacity of the atmosphere. Further, global climate models generally underestimate the effects of warming on extreme hydroclimatic events (23).

The implications of changing CVP for tree growth vary across the conterminous United States due to regional, seasonal, and species differences in the nature of the precipitation-growth relationship (Figs. 2 and 3). Tree growth at northern and high elevation sites (including Tsuga, Abies, and Picea species) showed little to no evidence of precipitation limitation (whether symmetric or asymmetric) in any season (Figs. 2 and 3), so any changes in CVP in these regions are unlikely to have major effects on growth, although it is possible that growth at some of these sites may respond to precipitation at shorter or longer time scales (e.g., monthly or annual) than examined in this research. However, in the semiarid regions of the western United States, growth typically responded positively, but asymmetrically, to cool-season 

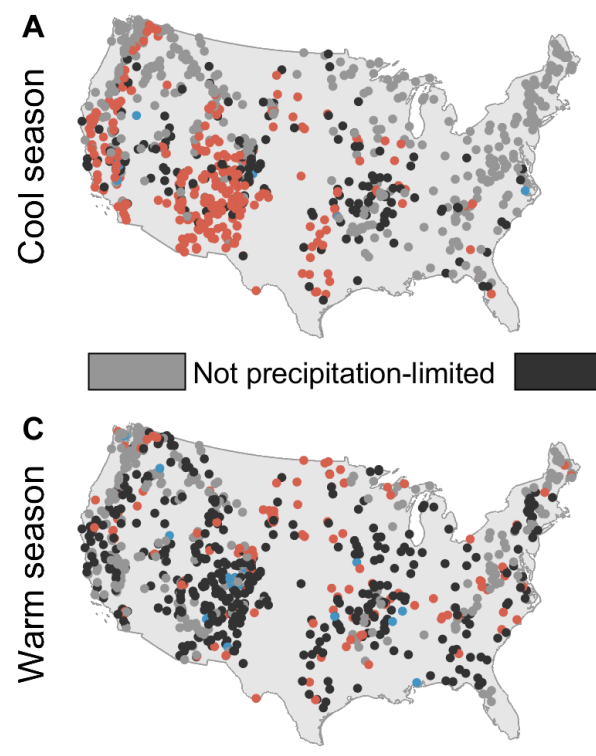

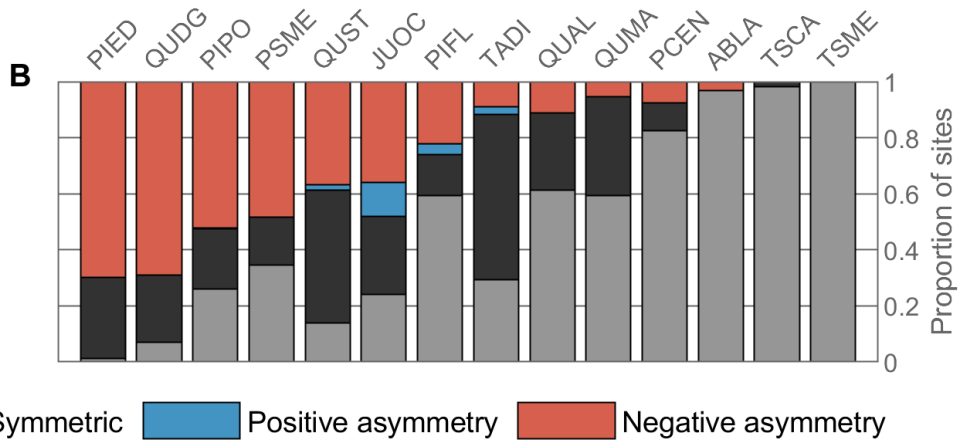

D

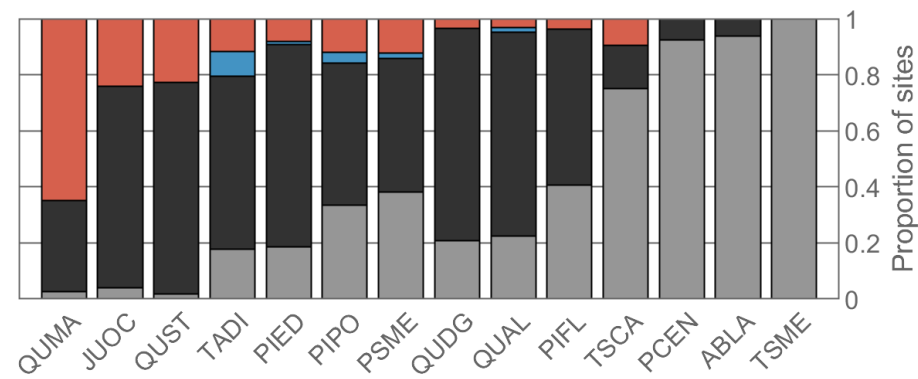

E

Not precipitation-

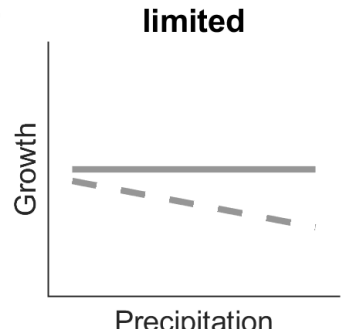

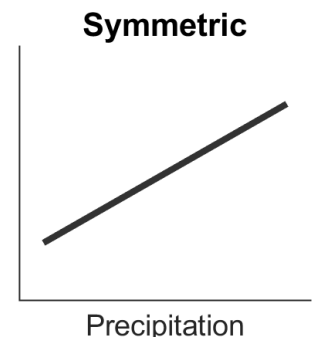

Precipitation

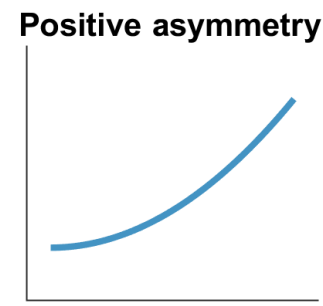

Precipitation

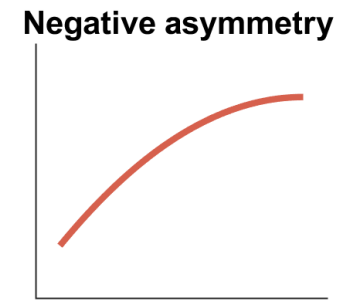

Precipitation

Fig. 2. Growth responses to six-month precipitation composites. Growth responses are shown for cool season precipitation (A and B) and warm season precipitation $(\mathbf{C}$ and $\mathbf{D})$. Relationships between tree growth and precipitation were defined as follows: not precipitation limited $\left(P>P_{\mathrm{FDR}}\right.$ or linear slope less than zero), symmetric $\left(P \leq P_{\mathrm{FDR}}\right.$ and $\mathrm{AIC}$ linear $\left.\leq \mathrm{AlC}_{\text {quadratic }}\right)$, a positive asymmetry $\left(P \leq P_{\mathrm{FDR}}\right.$ and $\mathrm{AlC}_{\text {linear }}>\mathrm{AlC}_{\text {quadratic }}$ with concave-up quadratic model $)$, and a negative asymmetry $\left(P \leq P_{\mathrm{FDR}}\right.$ and $\mathrm{AIC}_{\text {linear }}>\mathrm{AIC}$ quadratic with concave-down quadratic model). Response functions were calculated from 1895 (the start of the PRISM precipitation estimates) through the ending year of tree-ring measurements, which varied by site but was never earlier than 1970. (B and D) Proportion of sites characterized as each response type for all species with at least 25 sites in the tree-ring database. Species include Abies lasiocarpa (ABLA, 32 sites), J. occidentalis (JUOC, 25 sites), Picea engelmannii (PCEN, 40 sites), P. edulis (PIED, 86 sites), Pinus flexilis (PIFL, 27 sites), P. ponderosa (PIPO, 215 sites), P. menziesii (PSME, 197 sites), Q. alba (QUAL, 62 sites), Q. douglasii (QUDG, 29 sites), Q. macrocarpa (QUMA, 37 sites), Q. stellata (QUST, 57 sites), T. distichum (TADI, 34 sites), Tsuga canadaensis (TSCA, 52 sites), and Tsuga mertensiana (TSME, 46 sites). (E) Conceptual diagrams of the four response types in (A) to (D).

precipitation (Fig. 2A) such that increasing precipitation yields diminishing returns for growth (a "negative asymmetry"). This asymmetry was particularly pronounced for the three most common species in the U.S. tree-ring database: piñon pine (Pinus edulis), Douglas-fir (Pseudotsuga menziesii), and ponderosa pine (Pinus ponderosa) (Fig. 2B). Dividing the precipitation into shorter seasonal composites (the traditional meteorological seasons) suggests that both prior autumn (September to November; Fig. 3, A and B) and winter (December to February; Fig. 3, C and D) precipitation contributed to the cool-season precipitation responses of these three species, although asymmetric relationships were more widespread for winter than autumn precipitation. Blue oak (Quercus douglasii) also responded asymmetrically to cool-season precipitation at more than $60 \%$ of sites (Fig. 2B), but this was driven almost entirely by strong responses to winter precipitation (Fig. 3, C and D), with very little contribution of prior autumn precipitation (Fig. 3, A and B). Evidence of positive asymmetries (i.e., where increasing precipitation yields increasing growth returns) was limited to only a small number of sites across the United States, primarily consisting of western juniper (Juniperus occidentalis). Among central and eastern U.S. species, both post oak (Quercus stellata) and bald cypress (Taxodium distichum) showed evidence of cool-season precipitation limitation at more than $60 \%$ of sites. Bald cypress responses were mostly symmetric, but post oak responses were split nearly evenly between symmetric and negative asymmetric relationships (Fig. 2B), with stronger (and more asymmetric) responses to winter precipitation than to prior autumn precipitation (Fig. 3, A and D).

Responses of tree growth to warm-season precipitation were predominantly symmetric (Fig. 2, C and D), with the exception of bur oak (Quercus macrocarpa), which responded asymmetrically to warm-season precipitation at more than $60 \%$ of sites (Fig. 2D). Other eastern oak species [white oak (Quercus alba) and post oak] were also limited by warm-season precipitation at roughly $80 \%$ or 

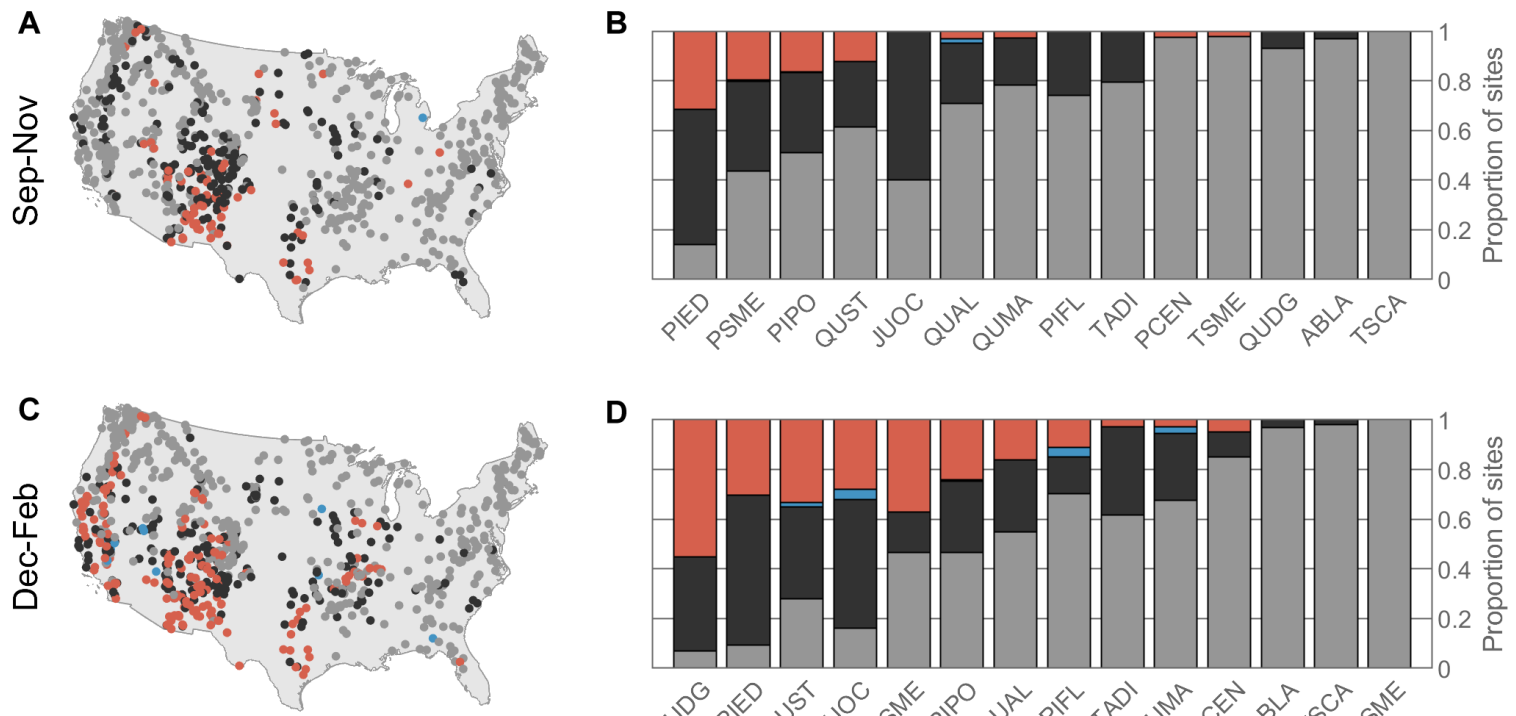

D
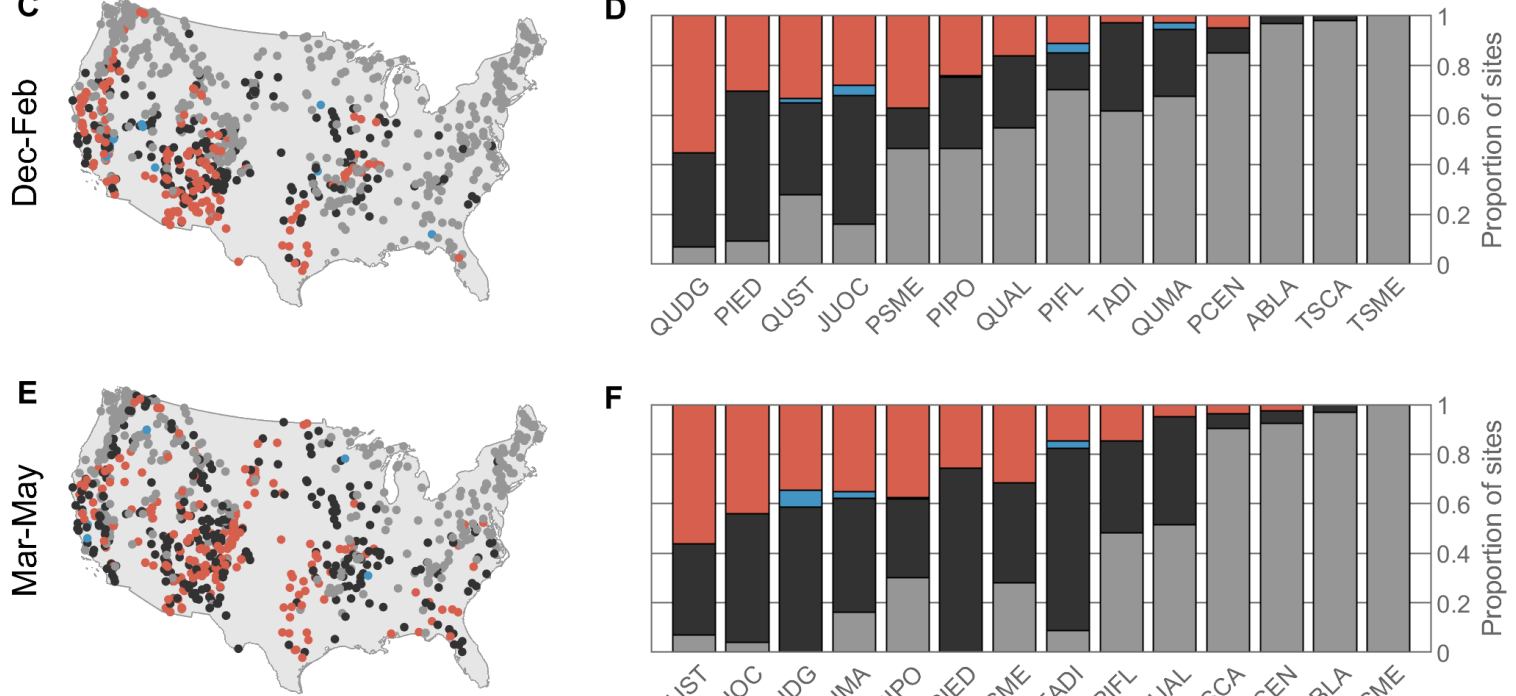

$\mathbf{F}$
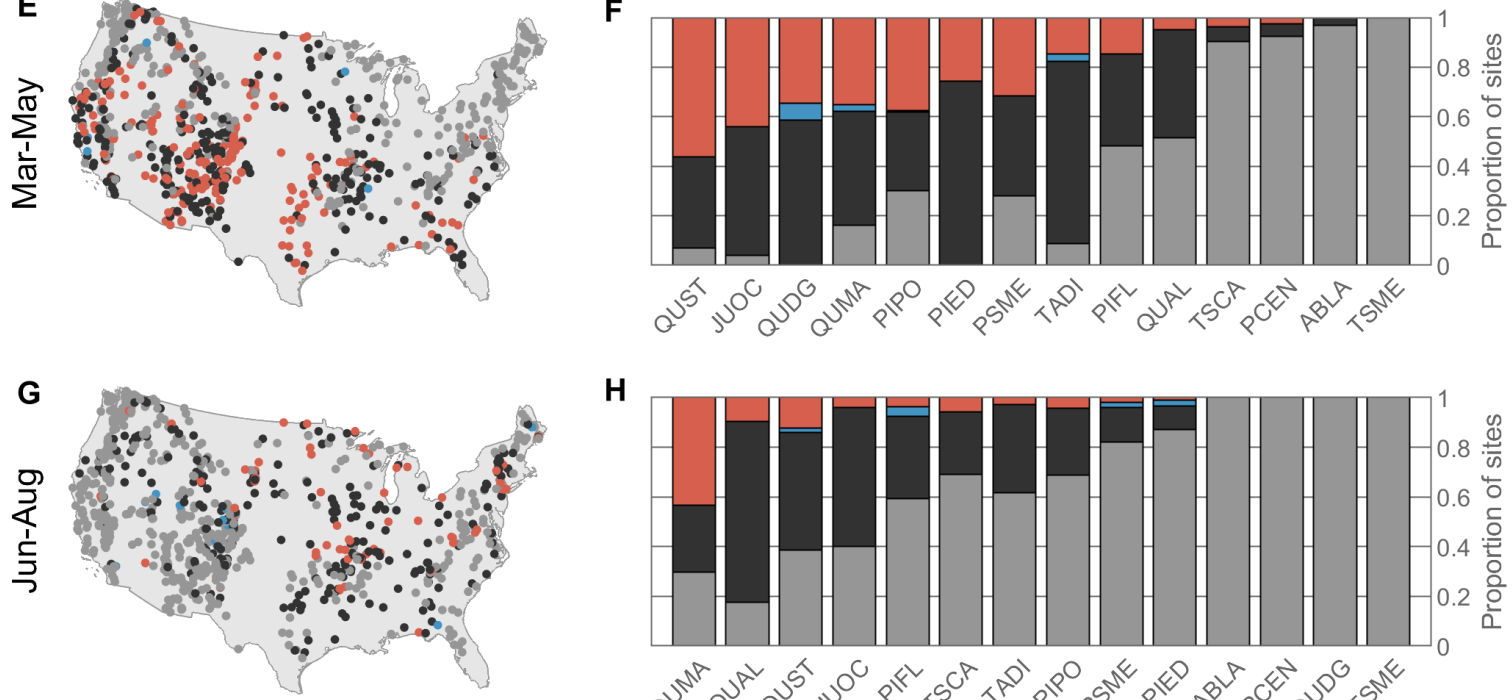

$\mathrm{H}$

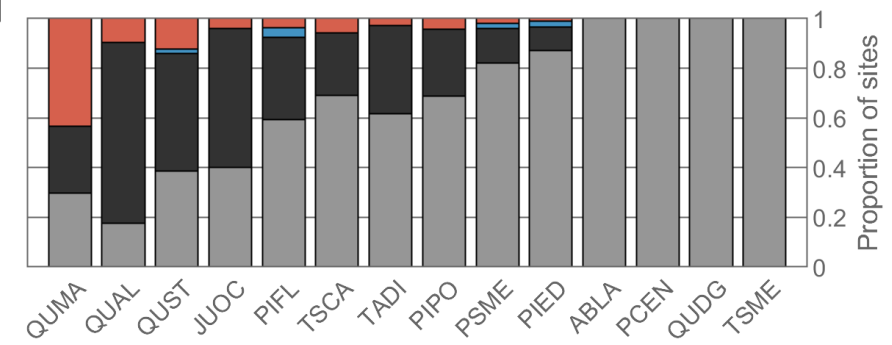

Not precipitation-limited

Symmetric

Positive asymmetry

Negative asymmetry

Fig. 3. Growth responses to 3-month seasonal precipitation composites. Growth responses are shown for prior autumn (September to November) precipitation (A and B), winter (December to February) precipitation (C and $\mathbf{D})$, spring (March to May) precipitation (E and $\mathbf{F})$, and summer (June to August) precipitation (G and $\mathbf{H})$. All methods, symbols, and species are identical to those shown in Fig. 2.

more of the sites, but these responses were predominantly symmetric. Dry-adapted western U.S. species-including western juniper, ponderosa pine, piñon pine, Douglas-fir, and blue oak-were positively correlated with warm-season precipitation at more than $60 \%$ of sites (Fig. 2D), but these relationships were also predominantly symmetric. Of the overlapping 3-month meteorological seasons, spring (March to May) precipitation was a particularly important driver of growth nearly everywhere except in the northeastern United States, west of the Cascade Mountains, and surrounding the Great Lakes (Fig. 3, E and F). Nearly all central and western oak sites ( $>80 \%$ of post oak, blue oak, and bur oak sites) and most western conifer sites ( $>70 \%$ of western juniper, ponderosa pine, piñon pine, and Douglas-fir sites) responded significantly, whether symmetrically or asymmetrically, to spring precipitation (Fig. 3F). Spring precipitation was also the most important season for bald cypress growth, with more than $90 \%$ of sites responded significantly (but mostly symmetrically) to precipitation during this season (Fig. 3F). By comparison, growth of most species did not show evidence of summer (June to August) precipitation limitation (Fig. 3, G and H), although in some cases (such as in southern California) this was probably driven not by lack of water stress but by the absence of summer precipitation in this Mediterranean climate. Of those species with at least 25 sites in the U.S. International Tree-Ring Data Bank (ITRDB), only four (bur oak, white oak, post oak, and western juniper) responded significantly to summer precipitation at more 
than half of the sites (Fig. $3 \mathrm{H}$ ). Those responses were predominantly symmetric except for bur oak, which responded asymmetrically to summer precipitation at more than $40 \%$ of sites and could therefore be particularly vulnerable to summer drought and possible increases in summer precipitation variability.

Widespread asymmetric relationships between tree growth and precipitation, especially during the cool season in semiarid regions of the western United States, meant that extremely dry years were very likely to be years with extremely low growth (Fig. 4; Materials and Methods). However, growth was far less likely to be extremely high following extremely wet cool seasons (Fig. 4B): Only 91 sites-mostly in southern California, Arizona, and New Mexico-exhibited significant overlap between extremely wet cool-season conditions and extremely high growth. In other words, while tree growth was very likely to be much reduced during extremely dry years, tree growth was not necessarily proportionately increased during extremely wet years, which is consistent with a fundamental principle of dendrochronology concerning the use of narrow rings as marker years for cross-dating samples $(24,25)$. Mean cool-season precipitation and mean cool-season temperature were important predictors of tree growth sensitivity to extreme precipitation, with drier and warmer sites exhibiting much stronger negative responses to extreme dryness relative to wetter and cooler sites (Fig. 5A and table S1). Even when accounting for differences in site climatologies, there were significant differences among species in their responsiveness to cool-season extremes (fig. S6, A and B, and table S1). These patterns generally did not hold as strongly for the April to September warm season, during which tree growth was less responsive to precipitation extremes (Fig. 4, C and D) irrespective of site-level mean precipitation (Fig. 5, C and D, and table S1), although warmer sites did tend to be more sensitive to extreme precipitation than cooler sites (table S1). However, the relative lack of response to warm-season extremes was likely due to relatively little summer precipitation limitation (fig. S7, G and H), whereas many sites, particularly those in the central and western United States, did respond significantly to spring precipitation extremes (fig. S7, E and F).

Asymmetric relationships between growth and precipitation could result in long-term negative growth trends if coupled to an increase in precipitation variability. Historically, there is clear evidence that these conditions co-occurred in the U.S. Southwest, where both a large increase in CVP (Fig. 1, C to F) and widespread negative asymmetries in growth responses to precipitation (Figs. 2 to 4 ) were observed. We therefore simulated the impact of the historical increase in precipitation variability, independent of a change in mean precipitation, on tree growth across this region. To examine potential impacts of the increased CVP on growth, we regressed a mean normalized growth index for the region (Materials and Methods) on mean regional cool-season precipitation, which explained about $61 \%$ of the regional growth variability, with a distinct negative asymmetry as observed in the site-level responses (fig. S8). To simulate long-term growth responses to the observed increase in CVP across the region, we generated two long (10,000-year) synthetic runs of precipitation drawn from (i) a gamma distribution fit to observed early 20th century precipitation (1901-1930) and (ii) a gamma distribution with the same mean as the early 20th century but with the elevated CVP observed during 1981-2010. We then simulated growth under

\section{Low precipitation extreme}

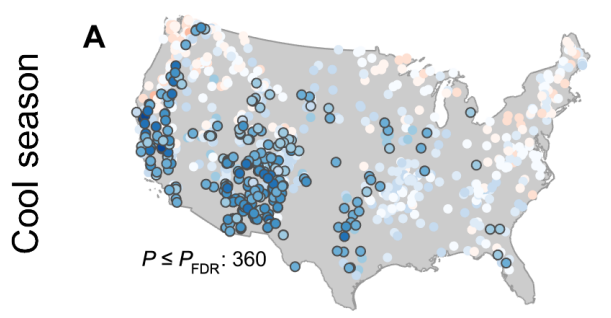

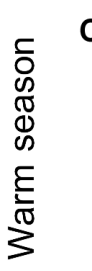

\section{High precipitation extreme}

B

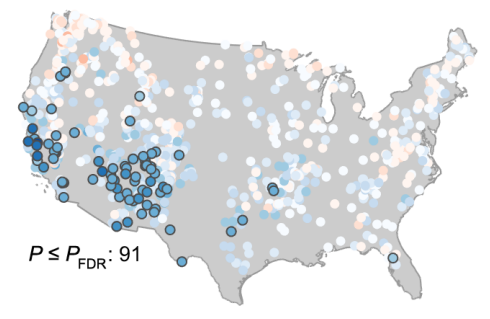

D

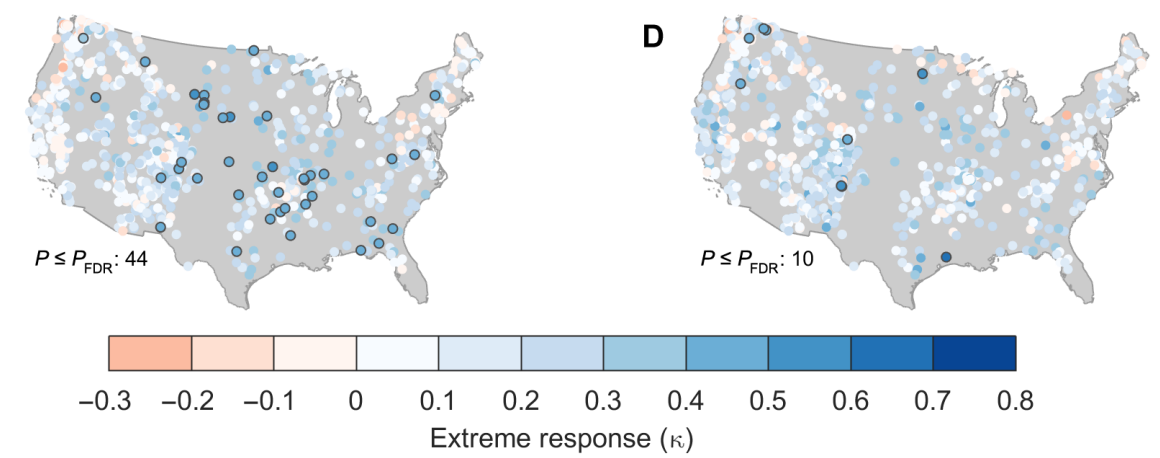

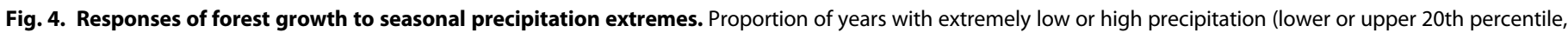

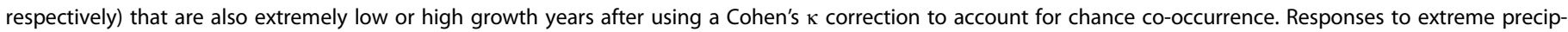

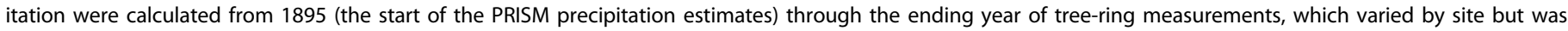

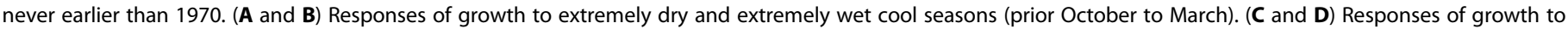

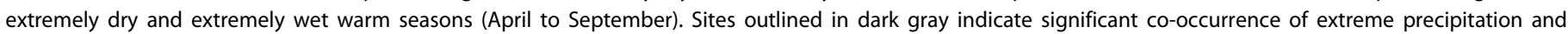

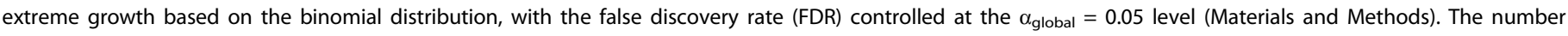
of sites where $P \leq P_{\mathrm{FDR}}$ is shown for each panel. 

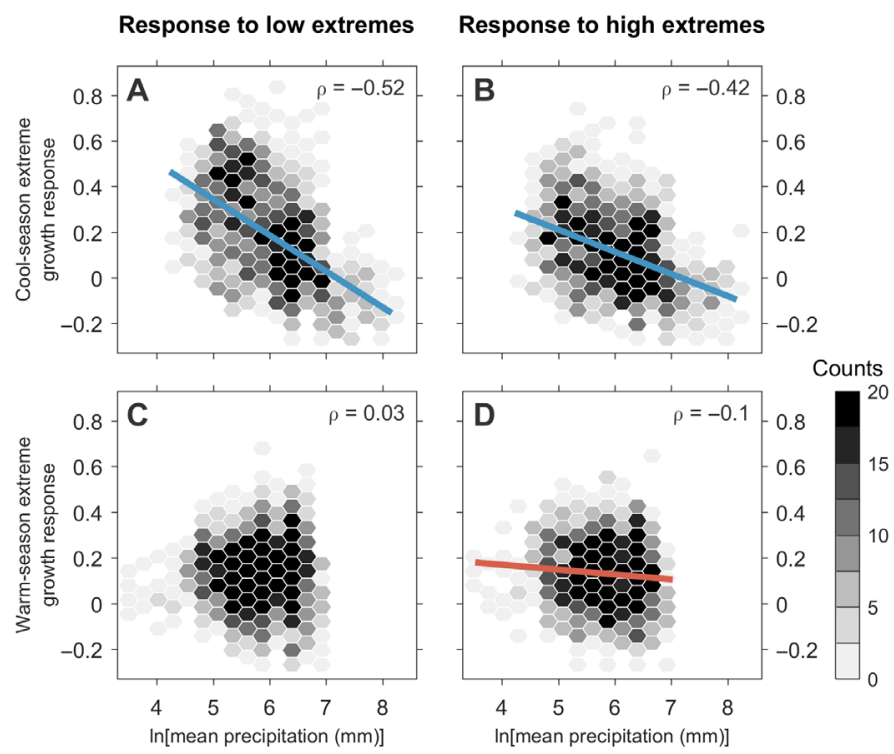

Fig. 5. Density plots showing the relationship between growth responses to extreme events and site-level mean precipitation from all sites $(N=1314)$. (A and B) Relationship between log-transformed cool-season mean precipitation and, respectively, the proportion of years with extremely low and high cool-season precipitation that are also years with extremely low and high growth, after correcting for chance agreement using Cohen's $\kappa$. (C and D) Relationship between log-transformed warm-season mean precipitation and, respectively, the proportion of years with extremely low and high warm-season precipitation that are also years with extremely low and high growth, after correcting for chance agreement using Cohen's $\kappa$. The linear relationship between log-transformed mean precipitation and growth responses to extremes is shown with blue lines (cool season) and red lines (warm season) for those with significant $(P<0.05)$ relationships, along with Spearman's rank correlation coefficient ( $\rho)$.

these precipitation scenarios using the fitted regional precipitationgrowth relationship plus white noise based on draws from the normal distribution defined from the residuals of the regional precipitationgrowth relationship (fig. S8 and Materials and Methods).

While the two regional cool-season precipitation simulations had the same mean precipitation (roughly $190 \mathrm{~mm}$ year $^{-1}$ ), the 1981-2010 simulation had a wider, flatter distribution with much higher probabilities of both extremely low and extremely high precipitation years (Fig. 6, A and B). The probability of cool-season precipitation of $100 \mathrm{~mm}$ or less in any given year more than tripled under the high variability scenario, from less than $3 \%$ during the $1901-1930$ period to nearly $10 \%$ during the 1981-2010 simulation (Fig. 6A). The increased likelihood and frequency of extreme precipitation in the high CVP simulation, combined with the strong negative asymmetry in regional precipitation-growth relationships, resulted in roughly a twofold increase in the probability of mean regional growth anomalies at least $1 \mathrm{SD}$ below historical norms, and this increase in the probability of low growth was not offset by an increased likelihood of high growth, which remained virtually unchanged between the two simulations (Fig. 6C). While a linear precipitation-growth relationship would result in higher variability but no change in mean growth (fig. S9), the widespread negative asymmetries in the U.S. Southwest resulted in lower mean growth under the high CVP scenario (1981-2010) relative to the early 20th century simulation (Fig. 6D). In addition, the likelihood of multiyear runs of extremely low growth was much higher under the high CVP scenario (fig. S10), which, given the disproportionate impact of extended ex- treme events on both carbon uptake (26) and forest mortality (10), suggests severe consequences for forests in a more variable future.

\section{DISCUSSION}

Our study sheds new light on the distinct regional and seasonal trajectories that changing precipitation variability could have on U.S. forests. First, while many sites, particularly those in northern or high elevation regions, showed either little evidence of precipitation limitation or symmetric responses to precipitation (though they may respond differently at time scales other than those examined here), we find that asymmetric relationships to precipitation dominated the semiarid forests of the western United States, a region that has experienced a large historical increase in precipitation variability. These dryland forests are therefore likely to be most susceptible to any further increases in precipitation variability as the climate continues to warm. Some eastern oak species (post oak and bur oak in particular) also exhibit widespread asymmetric responses to precipitation that may portend future vulnerability to increases in precipitation variability. Second, we find that, with few exceptions, increases in cool-season precipitation variability (particularly during December to February) and spring precipitation variability are more likely to result in negative growth trends than increases in summer precipitation variability. While tree growth in much of the United States responded positively to changes in warm-season/summer precipitation, the vast majority of sites and species responded linearly (or symmetrically) to precipitation in these seasons, suggesting that increases in precipitation variability during these seasons would increase the variability of growth, but not the overall mean growth. The major exceptions are the bur oak sites of the central United States, which responded asymmetrically to warm-season precipitation at $>60 \%$ of sites and to summer precipitation at $>40 \%$ of sites.

Previous studies have documented long-term declines in forest growth and increases in forest mortality largely attributable to higher VPD and warmer temperatures, particularly in the southwestern United States $(9,27)$. Our findings suggest an additional climatic driver of declining tree growth that could further reinforce stresses resulting from a change in mean precipitation or VPD. An increase in precipitation variability alone, particularly during winter and spring months, can reduce growth of many U.S. tree species, especially those in the semiarid United States, due to asymmetric growth responses to precipitation, resulting in both higher growth variability and lower mean growth. The ecological consequences of this asymmetry between precipitation variability and tree growth in a warmer and more variable climate could be quite severe, as decreases in radial growth are linked to higher mortality risk (28). The combined risks of higher precipitation variability and higher VPD, which is an increasingly important driver of growth in a warming climate (8), could portend large increases in future moisture stress for many regions and tree species.

Why might tree growth, as expressed in tree-ring width, respond asymmetrically to precipitation? We suggest three possible hydrological and physiological mechanisms $(25,29)$. First, when precipitation is high, soil moisture levels may approach saturation and a larger fraction of the precipitation may end up as runoff, which would be unavailable to plants, resulting in little change in growth. Second, when precipitation is plentiful, plants may be limited by other factors (e.g., growing season length, nutrient availability, or incident photosynthetically active radiation), resulting in diminishing returns for any increase in precipitation above a threshold. Last, if moisture is plentiful, then 
A

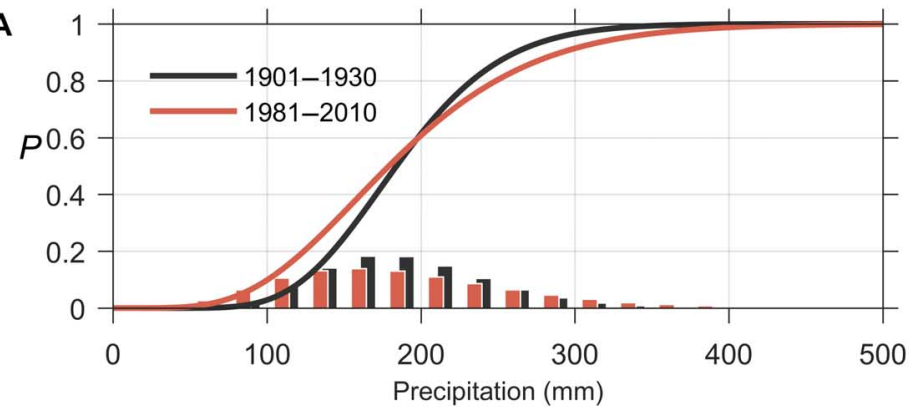

C

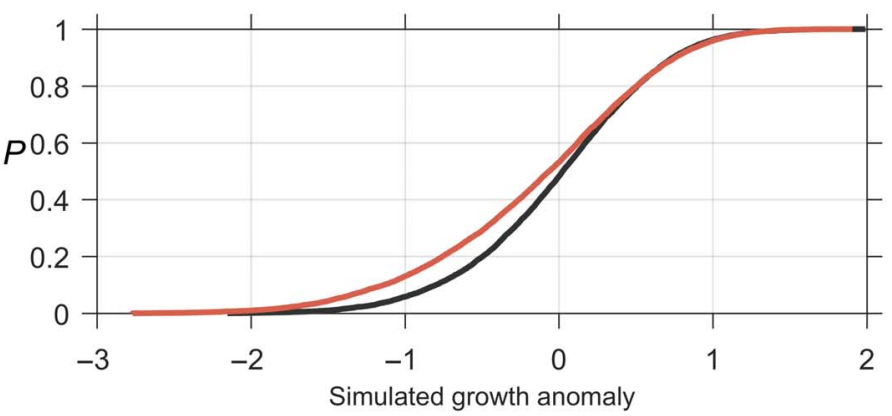

B

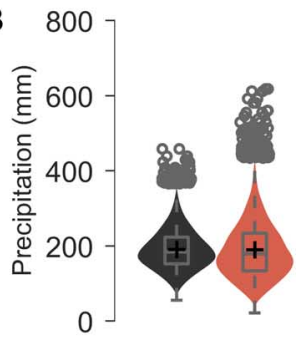

D

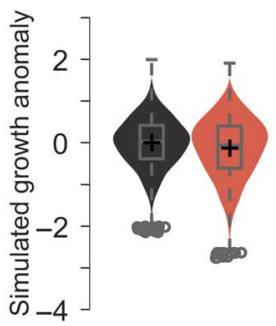

Fig. 6. Simulated implications of changing precipitation variability for tree growth in the southwestern United States (bounding box in Fig. 1A). (A) Cumulative and probability density functions (lines and bars, respectively) of the gamma distribution fit to regional cool-season precipitation. The 1901-1930 precipitation distribution was fit based on historical mean regional precipitation from PRISM, whereas 1981-2010 precipitation distribution was simulated with the same mean as 1901-1930 but with the observed increase in variability $\left(\mathrm{CVP}_{\text {historical }}\right)$. (B) Violin and box plots of 10,000 cool-season precipitation realizations derived from the gamma distributions in (A), which were used to simulate growth anomalies based on the observed sensitivity of regional growth to precipitation. The empirical cumulative density functions from these growth simulations are shown in (C), with accompanying violin and box plots in (D).

plants may alter the allocation of photosynthate to organs other than the stem or store the excess photosynthate as nonstructural carbohydrates, which could potentially allow the positive effects of high precipitation to carry over into subsequent years. If the widespread asymmetries between precipitation and growth observed in this study are attributable to changes in carbon allocation, then growth may be relatively more resilient to increased precipitation variability than suggested solely by examining tree-ring widths.

Until relatively recently $(14,19)$, the ecological impacts of changing precipitation variability, and thus the frequency and distribution of extreme events, have received less attention than other aspects of global change. However, it is these extreme events that have a disproportionate impact on forest mortality $(10,30)$ and the global carbon cycle (26), particularly in semiarid regions that are highly sensitive to variation in moisture availability and that are emerging as important drivers of the interannual variability of global terrestrial $\mathrm{CO}_{2}$ uptake $(31,32)$. The combination of higher precipitation variability with higher temperatures, higher VPD, and reduced snowpack could create novel climates that many species have not experienced during the comparatively stable Holocene. Unless plants are able to acclimate to these changes, or unless the negative impacts of higher VPD and CVP can be offset by positive impacts of longer growing seasons and/or $\mathrm{CO}_{2}$ fertilization [for which there is limited evidence in fieldbased studies of tree growth (33)], many forests may experience continued degradation and thus reduced carbon uptake capacity with important implications for climate change policy and mitigation strategies.

We note, however, that the tree-ring database used here likely includes a disproportionate number of sites under relatively high stress, which can accentuate and overestimate the observed growth response to climate variability (34). Our findings thus likely represent an upper threshold on asymmetric responses of tree growth to precipitation variability. In addition, the tree-ring database does not adequately represent the structure of eastern U.S. forests (35), and the growth responses to climate variability in this region tend to be highly complex (36). Our findings therefore pertain most strongly to dryland conifer forests of the western United States, while greater uncertainty likely exists in the more mesic and diverse forests of the eastern United States. We also caution that our findings pertain only to the time scales (3- to 6-month seasons) that were explicitly examined in this research. Although not common, growth responses to precipitation can be dominated by a single month (37), so the seasonal aggregations used here could mute some subseasonal responses of tree growth to precipitation. Additional research efforts are therefore needed to better understand how sensitivity to precipitation variability varies along stress gradients and across temporal scales while better capturing responses of structurally and taxonomically diverse eastern U.S. forests. Future research is also needed to examine the temporal stability of these relationships and possible interactions between decadal-scale climate fluctuations (e.g., the El Niño-Southern Oscillation or the Pacific Decadal Oscillation) and secular trends in precipitation variability that could result in protracted periods of unfavorable growth conditions.

\section{MATERIALS AND METHODS}

\section{Historical and projected precipitation}

We obtained monthly, 4-km gridded precipitation estimates for the period 1895-2016 from the PRISM Climate Group (38), from which we calculated 6-month seasonal precipitation totals for the cool season (October of the prior year through March) and the warm season (April through September). To quantify the variability of precipitation 
within each season, we calculated the CVP during two 30-year periods: the early 20th century (1901-1930) and the late 20th/early 21st century (1981-2010). CVP, expressed as a percent, was defined as CVP $=100 \times \frac{s}{\bar{x}}$, where $\bar{x}$ and $s$ are the sample mean and SD (standard deviation), respectively, during each 30-year period. Historical change in CVP $\left(\mathrm{CVP}_{\text {historical }}\right)$ was estimated as the difference between 1981-2010 CVP and 1901-1930 CVP:

$$
\Delta \mathrm{CVP}_{\text {historical }}=\mathrm{CVP}_{1981-2010}-\mathrm{CVP}_{1901-1930}
$$

Because the number of stations used to develop the gridded PRISM precipitation product was not constant through time, changes in station density could contribute to systematic bias and spurious long-term trends $(38,39)$. We therefore obtained monthly precipitation estimates from stations included in the USHCN (40) as further confirmation of the CVP change and to assess whether the PRISMestimated changes in CVP were an artifact of the interpolation process. The USHCN- and PRISM-estimated changes in CVP showed similar spatial patterns and magnitudes (Fig. 1, C to F) and were strongly correlated with each other (fig. S2; Pearson's correlation coefficients: $R=0.69$ for cool-season $\triangle \mathrm{CVP}$ and $R=0.74$ for warm-season $\triangle \mathrm{CVP}$ ), although the PRISM-estimated $\triangle \mathrm{CVP}$ was slightly higher than the USHCN-estimated $\triangle \mathrm{CVP}$ at the same locations (mean biases of $+2.71 \%$ and $+2.80 \%$ for the cool and warm seasons, respectively).

To assess projected change in CVP, we obtained monthly downscaled historical (1950-2005) and projected (2006-2100) simulations of precipitation under the RCP8.5 scenario from 32 models included in CMIP5 (41), using only a single ensemble member (r1ilp1) per model to avoid overrepresentation of models with larger ensembles (42). All model output was downscaled to $1 / 8^{\circ}$ horizontal resolution using bias correction and spatial disaggregation $(20,21)$. The models used in this analysis are listed in table S2. We then calculated CVP and $\mathrm{CVP}_{\text {projected }}$, as described above, but for one historical period (1981-2010) and one future period (2071-2100) from the CMIP5 projections.

\section{Tree-ring data and processing}

We obtained tree-ring width measurements from the ITRDB for all sites in the conterminous United States that fully covered the period 1895-1970 (a total of 1314 sites; fig. S1). All sites were used in our analysis, but we limit our discussion to the most common of the 78 species in this dataset (those with at least 25 sites) to avoid overinterpreting results for species with few replicates. While the site-level sampling designs often used in dendrochronology preclude any analyses of long-term trends in growth (43), the relationship between annual growth and climate variability is robust to these sample design choices (43), making the ITRDB a suitable choice for our analyses, especially given its long-term data record and high spatial density in the United States. Ring widths were detrended using a stiff smoothing spline twothirds the length of each ring-width series (44) in the dplR package (45) of the R statistical computing environment. Detrended ring width indices were then averaged to a site-level chronology using Tukey's biweight robust mean and pre-whitened to remove serial autocorrelation (i.e., "residual" chronologies). Seasonal precipitation was extracted from the nearest grid cell of the PRISM climate data for model fitting and analysis.

\section{Statistical analysis}

We fit linear and quadratic ordinary least squares regression models between seasonal precipitation (predictor variable) and the detrended growth index (response variable). Response functions were calculated from 1895 (the start of the PRISM precipitation estimates) through the ending year of tree-ring measurements, which varied by site but was never earlier than 1970. Any sites where the slope of the linear model was negative or not significantly different from zero, when controlling the false discovery rate at $\alpha_{\text {global }}=0.05$ (46), were deemed to be not influenced by precipitation during that season. For the remaining sites, we selected the best model using the Akaike information criterion (AIC) (47), which penalizes the quadratic models for the additional parameter. Sites where $\mathrm{AIC}_{\text {linear }} \leq \mathrm{AIC}_{\text {quadratic }}$ (i.e., where the linear model outperformed the quadratic model) responded "symmetrically" to precipitation (12). Sites where $\mathrm{AIC}_{\text {quadratic }}<\mathrm{AIC}_{\text {linear }}$ (i.e., where the quadratic model outperformed the linear model) responded "asymmetrically" to precipitation. These were further subdivided into "negative asymmetric" relationships (concave-down curves in which increasing precipitation has diminishing returns for growth) and "positive asymmetric" relationships (concave-up curves in which increasing precipitation has increasing returns for growth) (Fig. 2E). Because the 6-month cool/warm-season distinction may partly mask subseasonal growth responses of some species and regions, we also conducted the same analyses using seasonal precipitation totals in the traditional 3-month meteorological seasons starting with autumn (September to November) before the year of growth through summer (June to August) during the year of growth.

For each site, we divided the historical seasonal precipitation into low and high extremes, defined as the lower and upper 20th percentiles, for both the cool/warm seasons and the 3-month meteorological seasons. We then calculated the proportion of extreme precipitation years that were also extreme growth years of the same sign (based on the lower and upper 20th percentiles of the ring-width indices), similar to the extreme value capture (EVC) index (48). We corrected this index for chance agreement using Cohen's $\kappa$ statistic (49)

$$
\kappa=\frac{\mathrm{EVC}-p_{0}}{1-p_{0}}
$$

where EVC is the proportion of extreme precipitation years that are also extreme growth years of the same sign and $p_{0}$ is the expected cooccurrence due to chance (i.e., 0.2). We tested the significance of cooccurrence between extreme precipitation and extreme growth using the binomial distribution (48) while again controlling the false discovery rate at the $\alpha_{\text {global }}=0.05$ level (46). We then used linear mixed effects models, with fixed effects for seasonal mean precipitation and temperature of each site and random intercepts by species, to examine the influences of geography versus species on site-level EVC in the cool and warm seasons.

On the basis of the above analyses, we simulated potential impacts of the historical increase in cool-season CVP on growth in the U.S. Southwest (defined as $32^{\circ} \mathrm{N}-37^{\circ} \mathrm{N}, 122^{\circ} \mathrm{W}-108^{\circ} \mathrm{W}$; Fig. $1 \mathrm{~A}$ ), a region characterized by high interannual precipitation variability, a large historical increase in CVP, and a distinct negative asymmetry in precipitation-growth relationships. We calculated mean annual cool-season precipitation within this region from PRISM data, as well as annual standardized growth anomalies at each site, which were averaged together to form a regional growth index. We then fit a regional precipitation-growth relationship for the Southwest following the same methods described above for the site-level relationships, and examined the fit of the model as well as the distribution, serial 
autocorrelation, and heteroskedasticity of the residuals (fig. S6). A Lilliefors test of normality failed to reject $(P>0.05)$ the null hypothesis that the residuals were drawn from a normally distributed population (fig. S5B), and the residuals exhibited low $(P>0.05)$ serial autocorrelation at nearly all time lags (fig. S5C) and were not strongly heteroskedastic (fig. S5D).

To simulate the potential impacts of higher precipitation variability on growth, we generated two synthetic 10,000-year runs of cool-season precipitation variability under two scenarios: (i) based on random draws from a gamma distribution fit to early 20th century (1901-1930) observed precipitation and (ii) based on random draws from a gamma distribution with the 1901-1930 mean precipitation but with the PRISM-estimated 1981-2010 CVP (Fig. 5, A and B). This allowed us to simulate the potential impacts of an increase of precipitation variability alone, independent of any change in mean precipitation. We simulated growth under these scenarios by applying the fitted Southwest regional precipitation-growth relationship to the simulated precipitation time series, with noise simulated with random draws from a normal distribution with a mean of zero and variance defined by the residuals of the regional precipitation-growth model (fig. S5B). We then examined the empirical cumulative distribution functions of simulated growth under each scenario to estimate changes in long-term regional mean growth and changes in the probability of extreme low and high growth as a result of an increase in precipitation variability alone.

\section{SUPPLEMENTARY MATERIALS}

Supplementary material for this article is available at http://advances.sciencemag.org/cgi/ content/full/5/10/eaaw0667/DC1

Fig. S1. ITRDB sites used in these analyses $(N=1314)$.

Fig. S2. Comparison of historical CVP change between PRISM ( $\triangle$ CVPPRISM) and the UHCN ( $\triangle$ CVPUSHCN).

Fig. S3. Historical changes in PRISM-derived CVP of the Southwest.

Fig. S4. Projected changes in cool-season CVP (1981-2010 versus 2071-2100) from each downscaled CMIP5 model.

Fig. S5. Projected changes in warm-season CVP (1981-2010 versus 2071-2100) from each downscaled CMIP5 model.

Fig. S6. Effect of species on the sensitivity of growth to precipitation extremes based on linear mixed effects models with random intercepts.

Fig. S7. Same as Fig. 4, but for the 3-month meteorological seasons.

Fig. S8. Model and diagnostics for the relationship between cool-season precipitation and growth in the Southwest.

Fig. S9. Same as Fig. 6, but with a linear, rather than asymmetric, growth relationship to precipitation.

Fig. S10. Number of multiyear runs (in the 10,000-year simulations) with simulated mean regional growth anomalies at least 1 SD below the historical mean.

Table S1. Coefficients (with SE and $P$ values) from linear mixed effects models of site-level low and high seasonal extreme responses $(\kappa)$.

Table S2. Downscaled CMIP5 models.

\section{REFERENCES AND NOTES}

1. D. L. Hartmann, A. M. G. K. Tank, M. Rusticucci, S. Brönnimann, Y. Charabi, F. Dentener, E. J. Dlugokencky, D. Easterling, A. Kaplan, B. Soden, P. W. Thorne, M. Wild, P. Zhai, Observations: Atmosphere and surface, in Climate Change 2013: The Physical Science Basis. Contribution of Working Group I to the Fifth Assessment Report of the Intergovernmental Panel on Climate Change, T. F. Stocker, D. Qin, G.-K. Plattner, M. Tignor, S. K. Allen, J. Boschung, A. Nauels, Y. Xia, V. Bex and P. M. Midgley, Eds. (Cambridge Univ. Press, 2013), pp. 159-254.

2. M. Collins, R. Knutti, J. Arblaster, J.-L. Dufresne, T. Fichefet, P. Friedlingstein, X. Gao, W.J. Gutowski, T. Johns, G. Krinner, M. Shongwe, C. Tebaldi, A.J. Weaver, M. Wehner, Long-term climate change: Projections, commitments and irreversibility, in Climate Change 2013: The Physical Science Basis. Contribution of Working Group I to the Fifth Assessment Report of the Intergovernmental Panel on Climate Change, T. F. Stocker, D. Qin, G.-K. Plattner, M. Tignor, S. K. Allen, J. Boschung, A. Nauels, Y. Xia, V. Bex, P. M. Midgley, Eds. (Cambridge Univ. Press, 2013), pp. 1029-1136.
3. A. G. Pendergrass, R. Knutti, F. Lehner, C. Deser, B. M. Sanderson, Precipitation variability increases in a warmer climate. Sci. Rep. 7, 17966 (2017).

4. W. Cai, S. Borlace, M. Lengaigne, P. van Rensch, M. Collins, G. Vecchi, A. Timmermann, A. Santoso, M. J. McPhaden, L. Wu, M. H. England, G. Wang, E. Guilyardi, F.-F. Jin, Increasing frequency of extreme El Niño events due to greenhouse warming. Nat. Clim. Chang. 4, 111-116 (2014).

5. V. Trouet, F. Babst, M. Meko, Recent enhanced high-summer North Atlantic Jet variability emerges from three-century context. Nat. Commun. 9, 180 (2018).

6. T. Tamarin-Brodsky, Y. Kaspi, Enhanced poleward propagation of storms under climate change. Nat. Geosci. 10, 908-913 (2017).

7. A. P. Williams, A. P. Williams, C. D. Allen, A. K. Macalady, D. Griffin, C. A. Woodhouse, D. M. Meko, T. W. Swetnam, S. A. Rauscher, R. Seager, H. D. Grissino-Mayer, J. S. Dean, E. R. Cook, C. Gangodagamage, M. Cai, N. G. McDowell, Temperature as a potent driver of regional forest drought stress and tree mortality. Nat. Clim. Chang. 3, 292-297 (2013).

8. K. A. Novick, D. L. Ficklin, P. C. Stoy, C. A. Williams, G. Bohrer, A. C. Oishi, S. A. Papuga, P. D. Blanken, A. Noormets, B. N. Sulman, R. L. Scott, L. Wang, R. P. Phillips, The increasing importance of atmospheric demand for ecosystem water and carbon fluxes. Nat. Clim. Chang. 6, 1023-1027 (2016).

9. D. D. Breshears, N. S. Cobb, P. M. Rich, K. P. Price, C. D. Allen, R. G. Balice, W. H. Romme, J. H. Kastens, M. L. Floyd, J. Belnap, J. J. Anderson, O. B. Myers, C. W. Meyer, Regional vegetation die-off in response to global-change-type drought. Proc. Natl. Acad. Sci. U.S.A. 102, 15144-15148 (2005).

10. C. D. Allen, D. D. Breshears, N. G. McDowell, On underestimation of global vulnerability to tree mortality and forest die-off from hotter drought in the Anthropocene. Ecosphere 6 , 129 (2015).

11. N. G. McDowell, A. P. Williams, C. Xu, W. T. Pockman, L. T. Dickman, S. Sevanto, R. Pangle, J. Limousin, J. Plaut, D. S. Mackay, J. Ogee, J. C. Domec, C. D. Allen, R. A. Fisher, X. Jiang, J. D. Muss, D. D. Breshears, S. A. Rauscher, C. Koven, Multi-scale predictions of massive conifer mortality due to chronic temperature rise. Nat. Clim. Chang. 6, 295-300 (2016).

12. A. K. Knapp, P. Ciais, M. D. Smith, Reconciling inconsistencies in precipitation-productivity relationships: Implications for climate change. New Phytol. 214, 41-47 (2017).

13. J. S. Hsu, P. B. Adler, Anticipating changes in variability of grassland production due to increases in interannual precipitation variability. Ecosphere 5, 58 (2014).

14. L. A. Gherardi, O. E. Sala, Enhanced precipitation variability decreases grass- and increases shrub-productivity. Proc. Natl. Acad. Sci. U.S.A. 112, 12735-12740 (2015).

15. K. R. Wilcox, Z. Shi, L. A. Gherardi, N. P. Lemoine, S. E. Koerner, D. L. Hoover, E. Bork, K. M. Byrne, J. Cahill Jr., S. L. Collins, S. Evans, A. K. Gilgen, P. Holub, L. Jiang, A. K. Knapp, D. LeCain, J. Liang, P. Garcia-Palacios, J. Peñuelas, W. T. Pockman, M. D. Smith, S. Sun, S. R. White, L. Yahdjian, K. Zhu, Y. Luo, Asymmetric responses of primary productivity to precipitation extremes: A synthesis of grassland precipitation manipulation experiments. Glob. Chang. Biol. 23, 4376-4385 (2017).

16. M. P. Dannenberg, E. K. Wise, Seasonal climate signals from multiple tree-ring metrics: A case study of Pinus ponderosa in the upper Columbia River basin. J. Geophys. Res. Biogeo. 121, 1178-1189 (2016).

17. M. Berkelhammer, I. C. Stefanescu, J. Joiner, L. Anderson, High sensitivity of gross primary production in the Rocky Mountains to summer rain. Geophys. Res. Lett. 44, 3643-3652 (2017).

18. J. M. Earles, J. T. Stevens, O. Sperling, J. Orozco, M. P. North, M. A. Zwieniecki, Extreme mid-winter drought weakens tree hydraulic-carbohydrate systems and slows growth. New Phytol. 219, 89-97 (2018).

19. L. L. Sloat, J. S. Gerber, L. H. Samberg, W. K. Smith, M. Herrero, L. G. Ferreira, C. M. Godde, P. C. West, Increasing importance of precipitation variability on global livestock grazing lands. Nat. Clim. Chang. 8, 214-218 (2018).

20. A. W. Wood, L. R. Leung, V. Sridhar, D. P. Lettenmaier, Hydrologic implications of dynamical and statistical approaches to downscaling climate model outputs. Clim. Change 62, 189-216 (2004).

21. E. P. Maurer, L. Brekke, T. Pruitt, P. B. Duffy, Fine-resolution climate projections enhance regional climate change impact studies. Eos Trans. Am. Geophys. Union. 88, 504 (2007).

22. F. Giorgi, E.-S. Im, E. Coppola, X. J. Gao, L. Mariotti, Y. Shi, Higher hydroclimatic intensity with global warming. J. Climate 24, 5309-5324 (2011).

23. E. M. Fischer, R. Knutti, Observed heavy precipitation increase confirms theory and early models. Nat. Clim. Chang. 6, 986-991 (2016).

24. M. A. Stokes, T. L. Smiley, An Introduction to Tree-Ring Dating (University of Chicago Press, 1968).

25. H. C. Fritts, Tree Rings and Climate (Academic Press, 1976).

26. J. Zscheischler, M. D. Mahecha, S. Harmeling, A. Rammig, E. Tomellari, M. Reichstein, Extreme events in gross primary production: A characterization across continents. Biogeosciences 11, 2909-2924 (2014).

27. D. D. Breshears, O. B. Myers, C. W. Meyer, F. J. Barnes, C. B. Zou, C. D. Allen, N. G. McDowell, W. T. Pockman, Tree die-off in response to global change-type drought: Mortality insights 
from a decade of plant water potential measurements. Front. Ecol. Environ. 7, 185-189 (2009).

28. M. Cailleret, S. Jansen, E. M. Robert, L. Desoto, T. Aakala, J. A. Antos, B. Beikircher, C. Bigler, H. Bugmann, M. Caccianiga, V. Čada, J. J. Camarero, P. Cherubini, H. Cochard, M. R. Coyea, K. Čufar, A. J. Das, H. Davi, S. Delzon, M. Dorman, G. Gea-lzquierdo, S. Gillner, L. J. Haavik, H. Hartmann, A. M. Hereş, K. R. Hultine, P. Janda, J. M. Kane, V. I. Kharuk, T. Kitzberger, T. Klein, K. Kramer, F. Lens, T. Levanic, J. C. L. Calderon, F. Lloret, R. Lobo-Do-Vale, F. Lombardi, R. L. Rodríguez, H. Mäkinen, S. Mayr, I. Mészáros, J. M. Metsaranta, F. Minunno, W. Oberhuberia, A. Papadopoulos, M. Peltoniemi, A. M. Petritan, B. Rohner, G. Sangüesa-Barreda, D. Sarris, J. M. Smith, A. B. Stan, F. Sterck, D. B. Stojanović, M. L. Suarez, M. Svoboda, R. Tognetti, J. M. Torres-Ruiz, V. Trotsiuk, R. Villalba, F. Vodde, A. R. Westwood, P. H. Wyckoff, N. Zafirov, J. Martínez-Vilalta, A synthesis of radial growth patterns preceding tree mortality. Glob. Chang. Biol. 23, 1675-1690 (2017).

29. F. S. Chapin, P. A. Matson, P. M. Vitousek, Principles of Terrestrial Ecosystem Ecology (Springer, ed. 2, 2011).

30. N. McDowell, W. T. Pockman, C. D. Allen, D. D. Breshears, N. Cobb, T. Kolb, J. Plaut, J. Sperry, A. West, D. G. Williams, E. A. Yepez, Mechanisms of plant survival and mortality during drought: Why do some plants survive while others succumb to drought? New Phytol. 178, 719-739 (2008).

31. B. Poulter, D. Frank, P. Ciais, R. B. Myneni, N. Andela, J. Bi, G. Broquet, J. G. Canadell, F. Chevallier, Y. Y. Liu, S. W. Running, S. Sitch, G. R. van der Werf, Contribution of semi-arid ecosystems to interannual variability of the global carbon cycle. Nature 509, 600-603 (2014).

32. V. Humphrey, J. Zscheischler, P. Ciais, L. Gudmundsson, S. Sitch, S. I. Seneviratne, Sensitivity of atmospheric $\mathrm{CO}_{2}$ growth rate to observed changes in terrestrial wate storage. Nature 560, 628-631 (2018).

33. J. Peñuelas, J. G. Canadell, R. Ogaya, Increased water-use efficiency during the 20th century did not translate into enhanced tree growth. Glob. Ecol. Biogeogr. 20, 597-608 (2011).

34. S. Klesse, R. J. DeRose, C. H. Guiterman, A. M. Lynch, C. D. O'Connor, J. D. Shaw, M. E. K. Evans, Sampling bias overestimates climate change impacts on forest growth in the southwestern United States. Nat. Commun. 9, 5336 (2018).

35. S. Zhao, N. Pederson, L. D'Orangeville, J. HilleRisLambers, E. Boose, C. Penone, B. Bauer, Y. Jiang, R. D. Manzanedo, The International Tree-Ring Data Bank (ITRDB) revisited: Data availability and global ecological representativity. J. Biogeogr. 46, 355-368 (2019).

36. C. D. Canham, L. Murphy, R. Riemann, R. McCullough, E. Burrill, Local differentiation in tree growth responses to climate. Ecosphere 9, e02368 (2018)

37. F. Biondi, Are climate-tree growth relationships changing in North-Central Idaho, U.S.A.? Arctic Antarct. Alp. Res. 32, 111-116 (2018).

38. C. Daly, M. Halbleib, J. I. Smith, W. P. Gibson, M. K. Doggett, G. H. Taylor, J. Curtis, P. P. Pasteris, Physiographically sensitive mapping of climatological temperature and precipitation across the conterminous United States. Int. J. Climatol. 28, 2031-2064 (2008).

39. S. Strachan, C. Daly, Testing the daily PRISM air temperature model on semiarid mountain slopes. J. Geophys. Res. 122, 5697-5715 (2017).

40. M. J. Menne, C. N. Williams Jr., R. S. Vose, The U.S. Historical Climatology Network monthly temperature data, version 2. Bullietin Am. Meteorol. Soc. 90, 993-1008 (2009).

41. K. E. Taylor, R. J. Stouffer, G. A. Meehl, An overview of CMIP5 and the experiment design. Bull. Am. Meteorol. Soc. 93, 485-498 (2012).
42. N. S. Diffenbaugh, D. Singh, J. S. Mankin, Unprecedented climate events: Historical changes, aspirational targets, and national commitments. Sci. Adv. 4, eaao3354 (2018).

43. C. Nehrbass-Ahles, F. Babst, S. Klesse, M. Nötzli, O. Bouriaud, R. Neukom, M. Dobbertin, D. Frank, The influence of sampling design on tree-ring-based quantification of forest growth. Glob. Chang. Biol. 20, 2867-2885 (2014).

44. E. R. Cook, K. Peters, The smoothing spline: A new approach to standardizing forest interior tree-ring width series for dendroclimatic studies. Tree-Ring Bull. 41, 45-53 (1981).

45. A. G. Bunn, A dendrochronology program library in R (dpIR). Dendrochronologia 26 115-124 (2008).

46. D. S. Wilks, "The stippling shows statistically significant grid points": How research results are routinely overstated and overinterpreted and what to do about it. Bull. Am. Meteorol. Soc. 97, 2263-2273 (2016).

47. H. Akaike, A new look at the statistical model identification. IEEE Trans. Automat. Contr. 19, 716-723 (1974).

48. D. McCarroll, G. H. Young, N. J. Loader, Measuring the skill of variance-scaled climate reconstructions and a test for the capture of extremes. Holocene 25, 618-626 (2015).

49. J. Cohen, A coefficient of agreement for nominal scales. Educ. Psychol. Meas. 20, 37-46 (1960).

Acknowledgments: We thank three anonymous reviewers for comments that improved the manuscript. We also acknowledge the World Climate Research Programme's Working Group on Coupled Modelling, which is responsible for CMIP, and we thank the climate modeling groups (listed in table S2 of this paper) for producing and making available their model output. For CMIP, the U.S. Department of Energy's Program for Climate Model Diagnosis and Intercomparison provides coordinating support and led development of software infrastructure in partnership with the Global Organization for Earth System Science Portals. We also thank the producers and providers of the Downscaled CMIP3 and CMIP5 Climate and Hydrology Projections archive, the PRISM Climate Group at Oregon State University, and all contributors to the ITRDB. Funding: This work was supported by a contract from the Strategic Environmental Research and Development Program (SERDP; project number RC18-1322). Author contributions: M.P.D., E.K.W., and W.K.S. conceived the study. M.P.D. designed and conducted all analyses (with input from E.K.W. and W.K.S.) and wrote the manuscript. All authors contributed to interpretation of the results and revision of the manuscript.

Competing interests: The authors declare that they have no competing interests. Data and materials availability: PRISM climate data are available at http://prism.oregonstate.edu. Monthly USHCN data are available at https://www.ncdc.noaa.gov/ushcn/. Downscaled CMIP5 projections are available at https://gdo-dcp.ucllnl.org/downscaled_cmip_projections/. All tree-ring data are available from the ITRDB (https://www.ncdc.noaa.gov/data-access/ paleoclimatology-data/datasets/tree-ring).

Submitted 14 November 2018

Accepted 9 September 2019

Published 2 October 2019

$10.1126 /$ sciadv.aaw0667

Citation: M. P. Dannenberg, E. K. Wise, W. K. Smith, Reduced tree growth in the semiarid United States due to asymmetric responses to intensifying precipitation extremes. Sci. Adv. 5, eaaw0667 (2019). 


\section{ScienceAdvances}

\section{Reduced tree growth in the semiarid United States due to asymmetric responses to intensifying precipitation extremes}

Matthew P. Dannenberg, Erika K. Wise and William K. Smith

Sci Adv 5 (10), eaaw0667.

DOI: $10.1126 /$ sciadv.aaw0667

ARTICLE TOOLS

SUPPLEMENTARY

MATERIALS

REFERENCES

PERMISSIONS http://advances.sciencemag.org/content/5/10/eaaw0667

http://advances.sciencemag.org/content/suppl/2019/09/30/5.10.eaaw0667.DC1

This article cites 44 articles, 3 of which you can access for free http://advances.sciencemag.org/content/5/10/eaaw0667\#BIBL

http://www.sciencemag.org/help/reprints-and-permissions

Copyright (C) 2019 The Authors, some rights reserved; exclusive licensee American Association for the Advancement of Science. No claim to original U.S. Government Works. Distributed under a Creative Commons Attribution NonCommercial License 4.0 (CC BY-NC). 